\title{
ESTRATÉGIAS DE MANUTENÇÃO E REVITALIZAÇÃO \\ LINGUÍSTICA NO OESTE CATARINENSE
}

\author{
STRATEGIES OF LANGUAGE MAINTENANCE AND \\ REVITALIZATION IN THE WEST OF SANTA CATARINA
}

\author{
Cristiane Horst ${ }^{1}$, Marcelo Jacó $\mathrm{Krug}^{2}$, Ana Elizabeth Fornara ${ }^{3}$
}

\begin{abstract}
RESUMO: Com o presente artigo tem-se por objetivo traçar algumas estratégias que visem fomentar a manutenção de línguas minoritárias, autóctones e alóctones, na região Oeste Catarinense. A proposta é analisar as informações apresentadas nos sites das prefeituras municipais e no IBGE (Instituto Brasileiro de Geografia e Estatística) referentes às línguas presentes no oeste de Santa Catarina, buscando saber quais são as línguas minoritárias mencionadas na região para poder verificar qual a visibilidade que tais sites dão à presença de outras línguas, além do português brasileiro. A partir dessa análise, buscamos compreender a relação estabelecida entre língua e constituição de identidade étnica de grupos minoritários, e a influência de tal proposição nos processos de manutenção ou substituição linguística. À luz dos resultados, destacamos a importância da aplicação de estratégias de manutenção de línguas minoritárias em diferentes esferas, a salientar nas escolas, nas comunidades e nas famílias.
\end{abstract}

PALAVRAS-CHAVE: Diversidade linguística; Oeste Catarinense; Línguas minoritárias; Estratégias de manutenção de línguas minoritárias.

ABSTRACT: The aim of this article is to develop some strategies to foster the maintenance of minority, autochthonous and allochthonous, languages in the West of Santa Catarina. The proposition is to analyze the information available on the websites of city halls and IBGE (Brazilian Institute of Geography and Statistics) regarding the languages present in the West of Santa Catarina. In doing so, we seek to find out what minority languages are mentioned in the region, and thus verify the visibility such sites give to the presence of other languages besides Brazilian Portuguese. Based on this analysis, we will try to understand the relationship established between language and the constitution of ethnic identity of minority groups, and the influence of such a proposition on the processes of linguistic maintenance or substitution. We highlight the importance of developing strategies to maintain minority languages in different spheres, like schools, communities and families.

KEYWORDS: Linguistic diversity; West of Santa Catarina; Minority languages; Strategies to maintain minority languages.

\footnotetext{
${ }^{1}$ Doutora em Letras/Filologia Românica pelo Christian-Albrechts-Universität zu Kiel, Alemanha. Professora Adjunta da Universidade Federal da Fronteira Sul (UFFS).

${ }^{2}$ Doutor em Filologia Românica pela Christian-Albrechts-Universität zu Kiel, Alemanha. Professor Adjunto da UFFS.

${ }^{3}$ Graduanda do curso de Letras Português/Espanhol da UFFS.
} 


\section{Introdução}

Na região oeste de Santa Catarina, formou-se, ao longo de sua história, uma diversidade étnica e cultural bastante significativa. Até por volta do ano de 1900, ocupava a região, ao lado dos povos autóctones, Kaingang e Guarani, uma população de caboclos e mestiços, que vinham se refugiar na mata, fugidos de seus então "donos". A estes, ainda nas primeiras décadas do século XX, juntaram-se os povos alóctones, descendentes de imigrantes italianos, alemães, poloneses, russos e asiáticos, que passaram a fazer parte da paisagem linguística da região ${ }^{4}$. Essas minorias étnicas utilizam, até hoje, em diversos contextos, uma ou mais variedades linguísticas distintas do português ${ }^{5}$. No contato com esta língua majoritária, veem-se diante do dilema que acompanham as minorias: reafirmam-se como falantes de suas línguas de origem e as mantêm dentro de seus grupos, ou adotam os hábitos e a língua dominante do meio em que vivem. A opção do plurilinguismo, da competência em mais de uma língua pelo indivíduo, oferece-se como uma opção que atende ao duplo propósito da manutenção e integração linguística.

Ao longo dos anos, poucos foram os subsídios dados para que as línguas desses povos fossem mantidas. O Brasil foi marcado por políticas monolingualizadoras, entre as quais se mencionam especialmente os momentos de repressão linguística dos governos do Marquês de Pombal (1757) e do Estado Novo, na Era Vargas (1937-1945). Nesses períodos, ocorreu a proibição de línguas "faladas no lar ao lado ou em lugar do português". Como afirma Oliveira (2008), a imposição da ideia de um cenário de unidade da língua portuguesa brasileira construiu uma imagem equivocada do real panorama linguístico do Brasil, como sendo um país monolíngue, dominado pelo português, em toda a extensão de seu território. A omissão ou supressão da realidade plurilíngue, seja da coexistência de línguas ao lado das variedades do português brasileiro, seja da existência de falantes de mais de uma língua, contribuiu para retardar em algumas décadas ações que poderiam incentivar e utilizar positivamente o potencial do plurilinguismo brasileiro.

Diante desse cenário de repressão e estigmatização linguística, colocam-se, neste artigo, as seguintes perguntas em relação ao contexto particular da região oeste de Santa Catarina, de onde provém a grande maioria dos estudantes da Universidade Federal da

\footnotetext{
${ }^{4}$ Atualmente, a região oeste de Santa Catarina vem recebendo uma grande leva de haitianos, falantes do crioulo haitiano. Porém, ao tratarmos de línguas de imigração, não trataremos da língua crioula haitiana, haja vista a imigração recente desse povo, ainda em processo de mobilidade, e as restritas pesquisas linguísticas desenvolvidas sobre essa língua.

${ }^{5}$ Neste artigo, a variedade do português é representada pelo português rio-grandense, como acentua Altenhofen (2008), Horst e Krug (2012), Klein e Horst (2015).
} 
Fronteira Sul (UFFS), onde se desenvolve a pesquisa: a) Quais variedades linguísticas ainda são usadas nessa área (pergunta sobre o acervo, repertório, inventário das línguas)? b) De que maneira, esse acervo de línguas recebe a atenção do poder público, no âmbito da municipalidade?

Para analisar esses aspectos, buscamos informações na apresentação do histórico das localidades, nos sites das prefeituras municipais e do IBGE (Instituto Brasileiro de Geografia e Estatística), referentes às línguas presentes nos 76 municípios que formam o Oeste Catarinense, correspondendo às sub-regiões Caminhos da Fronteira e Grande Oeste. Buscamos saber quais são as línguas minoritárias mencionadas na região, na expectativa de verificar qual a visibilidade que tais sites dão à presença de outras línguas, além do português. A partir dessa análise, procuramos identificar a relação estabelecida entre essas línguas e a constituição da identidade étnica dos grupos minoritários, bem como seu impacto sobre a manutenção ou perda das línguas minoritárias locais, no uso e na memória dos membros da comunidade. Por fim, com base nesse diagnóstico, propõem-se estratégias que possam contribuir para a manutenção ou revitalização linguística, ou ao menos da conscientização do papel e presença dessas línguas como patrimônio cultural imaterial. Esse levantamento deverá fornecer subsídios para um projeto de pesquisa mais amplo do Atlas das Línguas em Contato na Fronteira: Oeste Catarinense, desenvolvido no âmbito da dialetologia pluridimensional e contatual, em que se buscará documentar, descrever e fomentar estudos sobre e para o plurilinguismo, nessa região.

A relevância desses aspectos justifica-se tanto interna- quanto externamente. De um lado, se nos apresenta uma realidade linguística complexa e multifacetada, em que indivíduos monolíngues ou monolíngues sem qualquer contato com outras línguas, além disso fixos na localidade, ou seja, sem nenhum histórico de migração, equivalem à exceção. Nessa complexidade, são afetadas diferentes áreas e setores da sociedade, desde o âmbito privado (relações de proximidade) até os âmbitos públicos - educacional, religioso, virtual e da administração local (relações de distância). Nos detemos, aqui, na visão oficial - da administração local - veiculada em sites de prefeituras. De outro lado, porém, ao descrever a dinâmica desses processos na sociedade, coloca-se a necessidade de rever e adequar os aspectos teóricos ao campo aplicado, no sentido de atender a uma demanda possivelmente "adormecida" na comunidade de falantes, qual seja de manter, salvaguardar ou revitalizar sua língua de grupo. Poderíamos falar, assim, em uma pesquisa-ação que conjuga a observação e entendimento dos fatos linguísticos (dimensão sociolinguística) com a intervenção, na sociedade, em decisões sobre as línguas e seu uso (dimensão político-linguística). 


\section{Contexto de estudo: a região Oeste Catarinense}

O Oeste Catarinense é formado por cerca de 76 municípios e faz divisa com os estados do Paraná, do Rio Grande do Sul e com a Argentina. Os municípios, de modo geral, são de área reduzida; muitos deles possuem menos de 5000 habitantes e se configuram como essencialmente rurais, pois predominam atividades agrícolas, sendo que a maior parte da população reside nas comunidades interioranas. Via de regra, até mesmo os habitantes do núcleo urbano provêm da área rural ou estabelecem uma relação de proximidade com esse meio.

Em relação ao processo de colonização dessa área, o Oeste Catarinense permaneceu, segundo Radin (2001), por muitos anos sem ser ocupado e explorado economicamente pelo homem branco. Não obstante, habitavam a região índios Kaingang que, segundo estudos arqueológicos, teriam chegado à região por volta de 5500 a.C. Aos poucos, no entanto, foram surgindo novos habitantes, como alguns bandeirantes, tropeiros, posseiros, refugiados de guerra e, principalmente, caboclos, que passavam pela região em busca dos campos do sul.

De acordo com Paim (2006, p. 5), a região oeste de Santa Catarina foi uma área de muitas disputas: primeiramente, entre Portugal e Espanha, depois entre Brasil e Argentina e, por fim, entre Paraná e Santa Catarina, culminando com a Guerra do Contestado (1912-1916). A partir dessa guerra, definiu-se efetivamente que a posse do território pertencia a Santa Catarina. Vale ressaltar que esses conflitos entre fronteiras foram determinantes para impulsionar a ocupação populacional desses espaços, seja para resguardar o direito de posse da terra, seja para se alinhá-los aos interesses do Estado, dando um aspecto "civilizatório" a uma região que, até então, era considerada "de ninguém”. Apesar da presença de indígenas e caboclos, tratava-se a região como fortemente despovoada e improdutiva, já que a população existente tinha modos de vida diferentes, não produziam excedentes para comercializar e não possuíam os títulos das propriedades, sendo por isso ignorados pelas autoridades.

Logo, o governo do Estado passou a distribuir as terras da região para aqueles que tinham algum tipo de prestígio político e econômico, e os beneficiados com as concessões montaram empresas colonizadoras para comercializar as terras. Vendedores passaram a fazer propagandas nas regiões agrícolas de colonização italiana e alemã, no Rio Grande do Sul, para atrair interessados. Foi essa promessa de "novas terras" que fez com que muitos colonos migrassem do Rio Grande do Sul para essa área oeste de Santa Catarina. Radin (idem, p. 24) ressalta que, com o avanço na ocupação dos territórios, o espaço, antes dos índios, reduzia-se cada vez mais. 
No que se refere à língua desses colonizadores, Radin (idem, p. 149), em seu trabalho acerca dos ítalo-brasileiros, ressalta que por muito tempo eles se mantiveram isolados em suas famílias e comunidades, assim, a língua de imigração manteve sua função de língua materna majoritária essencialmente usada na comunicação local, entre os membros do grupo. Mais tarde, e em consequência das ações de proibição e repressão de sua língua "de casa", restringiu-se o seu uso, no domínio público, portanto restrito ao domínio da família.

\section{Metodologia da coleta e base de dados}

Com o objetivo de verificar a presença de línguas minoritárias na região do Oeste Catarinense, analisaram-se os aspectos geográficos, históricos, políticos, econômicos, culturais e, sobretudo, linguísticos apresentados nos históricos da localidade, presentes em sites de prefeituras municipais e do IBGE. Com isso, procurou-se correlacionar o discurso oficial com o processo efetivo de formação da região. Para isso, utilizamos os dados obtidos pelo projeto de pesquisa Atlas das Línguas em Contato na Fronteira: Oeste Catarinense Cartografia (ALCF-OC), cujos levantamentos foram realizados entre 2015 e 2016.

A presença das línguas autóctones e alóctones (neste caso, línguas de imigração) presentes nos municípios que compõem a região foi correlacionada por meio da análise quantitativa das línguas e grupos mencionados. Adicionalmente à constatação do multilinguismo e do multiculturalismo explicitados ou não nos discursos oficiais, procedeu-se a uma análise (qualitativa) das descrições contidas nos históricos desses municípios, visando identificar uma relação entre a presença multilíngue e a identidade étnica local. À luz dos resultados, averiguamos a influência de tal relação nos processos de manutenção e substituição linguística, propondo ao final estratégias de manutenção e revitalização das línguas, para o contexto estudado. Essas estratégias referem-se a três esferas distintas, correspondentes à escola, à vida social nas comunidades e à família.

\section{Resultados da pesquisa: amostragem inicial}

De modo geral, os sites que fornecem os dados iniciais da pesquisa nem sempre especificam a língua, na verdade raramente apresentam qualquer dado relativo aos fatos linguísticos da municipalidade que retratam. As informações apresentadas referem-se primordialmente ao processo de colonização e formação étnica da região. Assim, podemos, em muitos casos, apenas "deduzir" de uma afirmação genérica sobre a presença de grupos 
imigrantes que ocuparam ou estão presentes nesse espaço que a ela se associa o dado adicional de que esses grupos falavam ou falam línguas próprias da história do grupo. Nosso interesse reside na pergunta se se reconhece (tem conhecimento) que "há presença de grupos diferentes que falam línguas diferentes do português”. Para complementar a análise, recorremos por isso a pesquisas empíricas pré-existentes que atestam essa correlação entre a existência de grupos imigrantes e a existência das línguas dos respectivos grupos, mais especificamente as seguintes dissertações de Mestrado que tratam de línguas minoritárias no Oeste Catarinense: Salvaro (2009), Ruscheinsky (2014), Curioletti (2015), Bortolotto (2015), Wehrmann (2016); Wolschick (2016), Wepik (2017) e Frizzo (2017). Além disso, Klein e Horst (2015) e Krug, Horst e Wepik (2016). A partir desse cruzamento de dados, inferimos que, na vinda e na atual presença dos descendentes de imigrantes de etnias diversas, encontramos também a presença das línguas minoritárias associadas a esses grupos correspondentes. O gráfico 1 resume os principais resultados desta primeira etapa de análise:

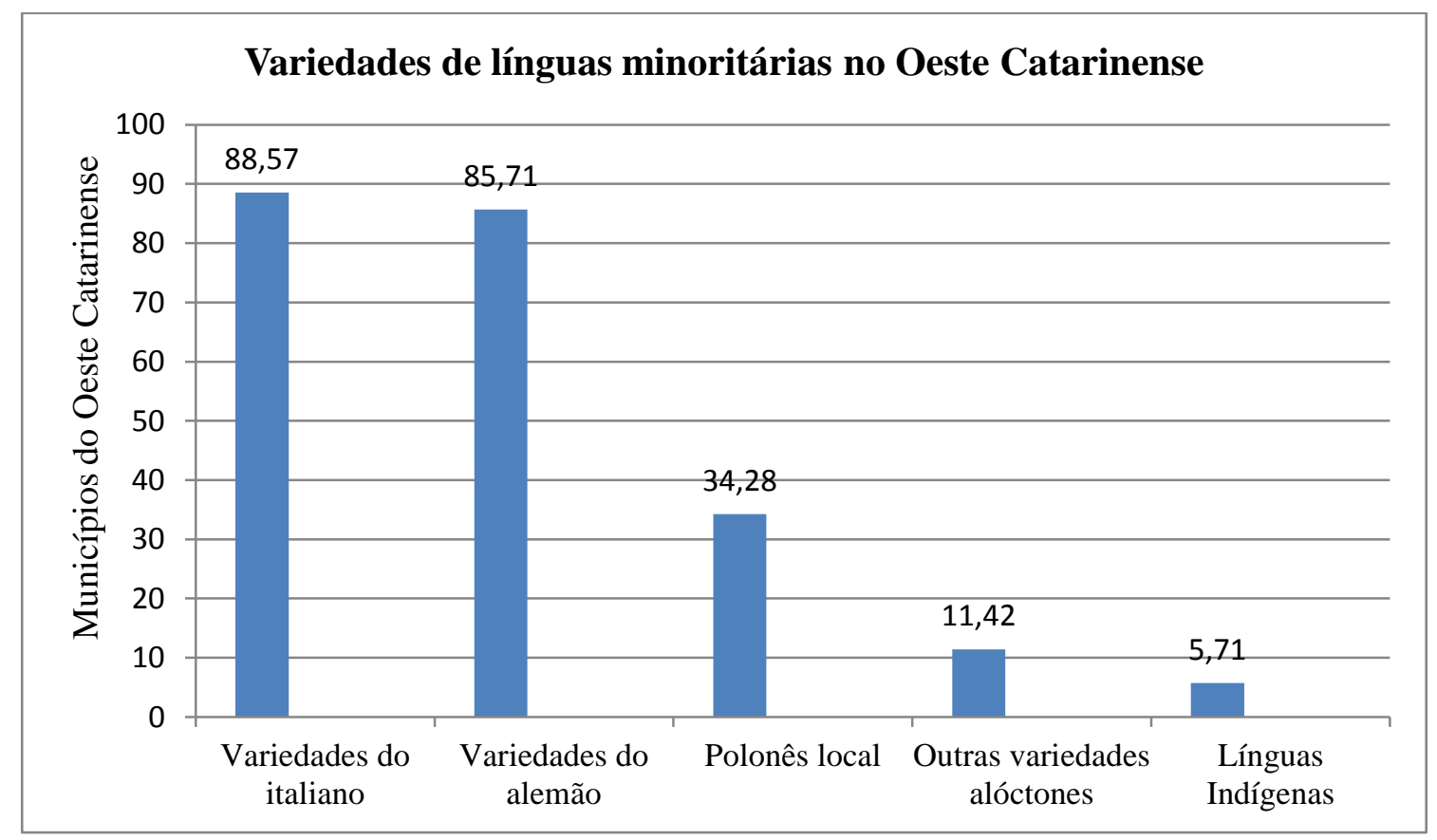

Gráfico 1: Variedades de línguas minoritárias no Oeste Catarinense registradas a partir da análise dos históricos presentes nos sites das 76 prefeituras municipais e no IBGE.

Conforme o gráfico acima, as variedades do italiano ${ }^{6}$ representam, por extensão à menção da presença de italianos e do que sabemos sobre esse grupo a partir dos estudos,

\footnotetext{
6 De acordo com o relatório final do projeto-piloto "Inventário do Talian", produzido na UCS, em 2010, o Talian constitui uma autodenominação dos falantes da RCI (Região de Colonização Italiana do RS) para uma variedade supra-regional, intracomunitária e intercomunidades do italiano como língua alóctone em contato com outras variedades do italiano e com o português do Brasil, vinculada historicamente aos dialetos provenientes do norte da Itália, mas com características próprias, derivadas do contexto brasileiro.
} 
88,57\% dos municípios do Oeste Catarinense, enquanto as variedades do alemão ${ }^{7}$ aparecem em 85,71\% dos municípios. Estas são as línguas minoritárias mais recorrentes na região; os índices apontam uma diferença mínima da presença dessas variedades em favor do italiano (pouco menos de 3\%). Por outro lado, a variedade do polonês local ${ }^{8}$ aparece mencionada em aproximadamente $34,28 \%$ dos municípios analisados. Restam ainda cerca de 11,42\% dos municípios que registram outras variedades alóctones, como o ucraniano ${ }^{9}$, o russo e o espanhol $^{10}$, além de $5,71 \%$ dos municípios em que se aponta a presença de grupos, por extensão línguas indígenas, Kaingang e Guarani ${ }^{11}$.

Cabe ressaltar que a menção dos grupos não traz qualquer asserção sobre a quantidade de prováveis falantes; apenas sinaliza a possibilidade de presença de falantes de variedades dessas línguas. Por isso, feito esse levantamento preliminar, é preciso ampliar as pesquisas, para verificar o real uso dessas línguas pelos falantes.

Contudo, é interessante observar que todos os municípios pesquisados apontam, em seus históricos, para o uso de ao menos uma língua minoritária além da variedade do português, sendo que mais da metade deles apontam para a presença de duas ou mais línguas minoritárias, ressaltando a composição de um território multilíngue. Em suma, todos os dados têm tendência à manifestação e explicitação da diversidade, nunca ao monolinguismo.

De acordo com Horst e Krug (2015, p. 3), o plurilinguismo que se faz presente em todo o cenário linguístico do sul do Brasil evoca diversas questões que são importantes para caracterizar a identidade linguística da região. O bilinguismo, fenômeno geográfico e social, configura já uma identidade territorial dessa área, embora apareça subsumido no conceito mais amplo do grupo étnico. Tal explica, em certa medida, a associação do sul do Brasil com a presença de populações falantes de línguas de adstrato em contato com o português. Essa identificação muitas vezes evocada pela mídia vem acompanhada de outros símbolos,

\footnotetext{
${ }^{7}$ O termo "variedades do alemão" designa as variedades Hunsrückisch e platt, encontradas no Oeste Catarinense. De acordo com Heye (2006, p. 70), essas duas variedades minoritárias se manifestam dependendo da origem dos descendentes dos imigrantes alemães. O Platt ou Plattdeutsch é formado por um conjunto de dialetos do norte da Alemanha, enquanto o Hunsrïckisch é uma categoria que engloba uma grande variedade de dialetos alemães de diferentes regiões, formando um conjunto pouco especificado e uniforme.

${ }^{8}$ Ver Krug, Horst e Wepik (2016) e Wepik (2017).

${ }^{9}$ Ver Scholtz (2014) na dissertação de mestrado Identidade e comportamento linguístico nas comunidades de Virmond $e$ Candói, no Paraná.

${ }^{10}$ Para mais detalhes sobre a constituição de uma língua de fronteira, ver Sella e Busse (2012).

${ }^{11}$ Ao longo do trabalho, propomo-nos a estudar também as línguas indígenas, porém, tanto do ponto de vista teórico, quanto do prático, tivemos dificuldades, uma vez que são poucos os estudos acerca das línguas indígenas no Oeste Catarinense. Esses estudos, em sua maioria, partem do viés linguístico em direção a um contexto histórico e antropológico. Diante de tal panorama, citamos os trabalhos de Salvaro (2009) e D’ Angelis (2002). Também ver Frizzo (2017), uma pesquisa linguística, na dissertação de mestrado Manutenção, Preservação e Perda do Bilinguismo: Português/Guarani/Kaingang na Reserva Guarita-RS.
} 
aparentemente com maior visibilidade, como por exemplo as festas tradicionais, paisagens turísticas, arquitetura, culinária, dança, etc. Ressalta-se, nessas associações, valores positivos que enaltecem o "lado belo" da cultura genericamente vista como europeia, mas que integra, em uma simbiose cultural, elementos do contato de culturas estrangeiras com diferentes culturas já presentes na região, no período de colonização. Para elucidar esse aspecto, vejamos o seguinte excerto retirado de um dos históricos municipais analisados:

\begin{abstract}
São João do Oeste possui pouco mais de 6000 habitantes e caracteriza-se por preservar a língua trazida da Alemanha. Preserva, também, diversos aspectos culturais entre eles a Deutsche Woche, uma semana cheia de atividades alusivas à imigração alemã no Brasil. Essas atividades relembram o passado e proporcionam descontração e brincadeiras que trazem para gerações presentes a cultura e a língua alemã. Marca disso é que cerca de $98 \%$ da população fala alemão e o município é intitulado a capital catarinense da língua alemã. A variedade é ensinada para os pequenos dentro de casa, nas escolas, mas também ouvida nas ruas, no cotidiano da população, um reflexo da cultura preservada. (PREFEITURA MUNICIPAL DE SÃO JOÃO DO OESTE. Disponível em: <http://www.saojoao.sc.gov.br/cms/pagina/ver/ codMapaItem/9656>. Acesso em: 15 de set. de 2016).
\end{abstract}

Neste exemplo, percebemos que a língua alemã é explicitamente apresentada como um produto cultural e histórico que identifica e diferencia a localidade, de grande valor para a comunidade de falantes, que não se restringe ao contexto familiar, mas também é utilizada na comunidade e na escola. Esse discurso afina com a recente cooficialização do alemão ao nível da municipalidade local. Apesar da variedade local predominante ser o hunsriqueano, o histórico da prefeitura, em São João do Oeste, omite esse dado, referindo-se de forma vaga à "língua trazida da Alemanha", como sendo exclusivamente uma forma do alemão-padrão. Silencia-se, nesse caso, os contatos linguísticos estabelecidos entre as diversas variedades linguísticas presentes na região. O alemão local, que construiu sua historicidade e agregou os elementos culturais e sociais do novo meio, seria o candidato natural a ser reconhecido como patrimônio cultural imaterial", como se coloca na política da diversidade linguística brasileira. Sem desemerecer o valor da língua internacional, essas marcas de brasilidade estão, de certo modo, ausentes na norma standard do alemão "reimportada da Alemanha".

Exemplo semelhante temos no município de Vargeão, localizado no meio oeste do Estado:

Os costumes e valores são característicos étnicos italianos, destacando-se o chimarrão, jogos de baralho (canastra, truco, bisca, etc.), cozinha italiana, churrasco, bebidas alcoólicas (vinho, cachaça, cerveja); cantos italianos, folclore gaúcho, festas e bailes tradicionais, festas juninas, futebol, bocha, bolão, rádio e televisão. (PREFEITURA MUNICIPAL DE VARGEÃO. Disponível em: <http://www.vargeao.sc.gov.br/cms/pagina/ver/codMapaItem/15422>. Acesso em: 15 de set. de 2016). 
O excerto acima salienta, como se pode ler, os traços étnicos italianos predominantes no município de Vargeão. Chama a atenção que, em nenhum momento, se aborda a presença da língua minoritária italiana, enquanto outros símbolos da cultura local são exaltados à exaustão. Segundo Horst e Krug (idem, p. 177), a língua é apenas um dos aspectos que afetam a identidade das comunidades multilíngues. Existem outros aspectos culturais que concorrem com a língua na expressão da identidade do grupo. Em muitas comunidades, os grupos de danças folclóricas, por exemplo, demarcam as fronteiras da própria etnia. Afinal, são comuns os casos de integrantes desses grupos que não falam mais a língua minoritária, mas que ainda assim possuem uma identidade forte ligada à etnia e à cultura da qual fazem parte. Outros elementos de valor simbólico para a identidade local, como as músicas, a arquitetura, as festas e bailes com denominações na língua minoritária, assim como pratos típicos e jogos, servem, nesse contexto, para "repotencializar" a identidade étnica e aumentam tanto o seu conceito, que parecem dispensar a língua dessa função. Ou seja, a língua local perde sua marca identitária, obrigatória para a etnia, e assume uma função apenas auxiliar. Abre-se, assim, o caminho para o domínio exclusivo do português e a consequente substituição da língua alóctone.

Processo semelhante ao que se observa em relação às línguas de imigração, é o que se observa com relação à línguas indígenas do passado. Assim como as denominações de ruas que lembram nomes de famílias colonizadoras, a toponímia de origem indígena aparece referida por quase toda a área. Chapecó, Itapiranga, Xanxerê e Campo Erê são exemplos de nomes derivados dessas línguas Kaingang e Guarani que foram atribuídos às localidades ainda em tempos mais remotos; nos textos analisados, são frequentes e recebem destaque as explicações da etimologia e gênese desse tipo de topônimo. Como exemplo, consideremos o seguinte excerto do histórico do município de Cunhataí:

\footnotetext{
Cunhataí recebeu esta denominação por influência indígena. Contam os mais antigos, pessoas daquela época, que os raros elementos de origem indígena que aqui viviam naquele tempo, ao verem as mulheres louras, filhas ou esposas dos pioneiros de origem alemã diziam: "Cunhataí". Palavra que mais tarde eles entenderam como moça bonita. Por essa razão, em homenagem a esta gente, batizaram a jovem comunidade de Cunhataí. (PREFEITURA MUNICIPAL DE CUNHATAÍ. Disponível em: <http://www.cunhatai.sc.gov.br/cms/pagina/ver/codMapaltem/11203>. Acesso em: 15 de set. de 2016).
}

Símbolos como estes, assim como no caso de nomes de famílias para denominar estabelecimentos comerciais e ruas, desempenham papel determinante na forma como os membros da comunidade vão construindo sua historicidade e identidade local. Esse papel é vale tanto pelo que coloca em evidência, quanto pelo que encobre, tendo em vista os rótulos 
que são construídos nesse processo e que tem um efeito de generalização muito grande. Como vimos, a língua recebe, além disso, a concorrência de outros fatores determinantes, na constituição da identidade étnica do grupo. Com isso, se abre o caminho para a substituição linguística, uma vez que sempre existirão outros ícones favorecendo a formação de uma identidade. Diante de tal perspectiva, consideramos necessárias propostas e ações que visem fomentar a manutenção das línguas minoritárias.

\section{Estratégias de manutenção das línguas minoritárias na escola}

Considerando o contexto escolar, a conscientização linguística voltada para a sensibilização à diversidade linguística e cultural é uma das estratégias mais importantes para promover a pluralidade linguística, consequentemente, a manutenção de línguas minoritárias. Não há manutenção, promoção ou revitalização linguística sem que exista a consciência por parte do falante do valor dessa língua e da importância dessa ação. A implementação de ações de conscientização linguística dá-se através da circulação do conhecimento e das diferentes vozes presentes na comunidade. Segundo Hawkins (1984) e Broch (2014), a sensibilização à diversidade linguística e cultural, entre outras coisas, favorece as representações e atitudes frente às línguas e o desenvolvimento de uma cultura linguística. Através dessa prática, os alunos modificam suas atitudes em relação às línguas e aos grupos que as utilizam, mostrando-se mais interessados pelas línguas e pelas culturas, obtendo melhores resultados escolares.

$\mathrm{Na}$ prática, a conscientização linguística pode ser trabalhada e desenvolvida de maneiras variadas. Um princípio básico que orienta esse processo é a "abertura" (ouverture linguistique) da escola, para além de seus muros, às línguas da comunidade. Na forma de oficinas, seminários e palestras referentes à presença, ao uso e à relevância identitária das línguas locais, a escola pode "abrir as portas" ás línguas locais, convidando pais, alunos e comunidade escolar de modo geral a "falar de si, sobre suas experiências linguísticas". Tal propósito inclui atividades de esclarecimento, melhor dizendo, de educação plurilinguística, como quer Broch (2014), em que se apresentam experiências de manutenção linguística e resultados de pesquisas e estudos realizados. A interface entre pesquisa e sociedade, falantes e linguistas, foi aliás um dos pilares que motivou a realização, em 2007, do I Seminário Internacional de Diversidade Linguística, que reuniu, no espaço universitário, falantes de diferentes línguas minoritárias. Também as artes, por meio por exemplo de apresentações 
teatrais e musicais, podem ser um aliado importante para ações de conscientização e promoção linguística.

No caso de línguas minoritárias, especialmente as línguas indígenas, coloca-se adicionalmente a necessidade de estabelecer um espaço de escrituralidade. Essa situação aumenta a relevância de projetos que fortaleçam a funcionalidade oral e escrita dessas línguas e que desenvolvam as habilidades orais e escritas dos falantes. Sobretudo comunidades indígenas, no Oeste Catarinense, já contam com escolas bilíngues na educação infantil, nas quais as crianças começam a estudar as duas línguas. Porém, no Ensino Médio, muitos alunos precisam se deslocar para as escolas do centro da cidade; em consequência, a língua indígena deixa de ser utilizada no contexto escolar, sendo paulatinamente substituída pelo português. Atividades que trabalham a estrutura das línguas Kaingang e Guarani, com o intuito de incentivar a criação de livros de histórias referentes às crenças e práticas tradicionais, a formação de um repertório de músicas e traduções na língua materna, e a elaboração de materiais de caráter informativo para a comunidade, como panfletos de prevenção a doenças, podem auxiliar no desenvolvimento da oralidade e da escrita dos alunos indígenas, em sala de aula.

Visto que não há um espaço específico destinado para o fomento das línguas minoritárias na escola, a elaboração e aplicação de oficinas pode representar, a curto prazo, uma forma menos complexa do que a instauração de um currículo bilíngue, para oportunizar o acesso ao conhecimento de variedades minoritárias. Sua implementação depende, no entanto, do grau de articulação e da abertura linguística disponibilizado pela escola e pelos professores a esse tipo de iniciativa. A estratégia, neste caso, consiste em ocupar espaços de direito, no sentido de um aménagement linguistique, como se procurou implementar no Canadá. Tal exige, no entanto, como defende Broch (idem, p. 199), que o professor assuma sua posição política linguística, para além das atividades em sala de aula, articulando ações e parcerias com professores de outras disciplinas. Ademais, é preciso ter consciência de que não são línguas estrangeiras para a maioria dos alunos, sendo necessários cuidados e sensibilidade para atingir as habilidades linguísticas de cada um. Contudo, vale ressaltar que há que se ter cuidado, pois muitos dos programas que propuseram o ensino de uma língua minoritária de imigração acabaram por facilitar ou abreviar esse processo, aderindo à simples oferta da língua-padrão correspondente. Com o intuito de fomentar a manutenção e revitalização linguística, tropeça-se em uma política linguística de difusão da língua padrão correspondente, ou seja, uma língua estrangeira moderna que muitas vezes repetem a exclusão linguística que motivou sua introdução na escola. 
Por fim, se a diversidade linguística ocorre e é parte marcante da realidade linguística do Oeste Catarinense, é importante que as escolas oportunizem aos seus alunos a conscientização dessa pluralidade, para que eles possam acompanhá-la, sentindo-se agentes de um processo. Assim, o trabalho em sala de aula deve conduzir o aluno para o entendimento da variação linguística como uma característica inerente a todas as línguas. Isso inclui, antes de tudo, a implementação de ações que promovam a conscientização linguística, abrindo espaço para línguas e culturas locais. Para os alunos, as atividades citadas acima podem favorecer a socialização, a sensibilização para as línguas e culturas da comunidade, bem como a motivação para o aprendizado das variedades minoritárias de seu entorno.

\section{Estratégias de manutenção de línguas minoritárias na comunidade}

Eberhard (2013) defende a ideia de que a decisão de investir em uma determinada língua minoritária deve sempre partir de um diálogo com a própria comunidade, um diálogo baseado na importância da abordagem participativa de toda a comunidade com os falantes, tomando as próprias decisões em favor de suas próprias línguas. Todas as entidades envolvidas devem compreender que as tentativas de manutenção e preservação de línguas minoritárias requerem um esforço intencional, contínuo e comunitário. Porém, para que isso ocorra são necessárias ações de sensibilização em relação às línguas também em nível comunitário.

Na situação em que as nossas línguas minoritárias se encontram, principalmente as de imigração, de perda da transmissão intergeracional, observamos a importância do fortalecimento da oralidade através de projetos que utilizem a mídia, em especial o áudio. Como exemplo, pode-se citar a criação e divulgação de programas em emissoras de rádios locais, em línguas minoritárias. Esses programas, entre outras coisas, podem ter um viés educativo, tematizando a cultura e as línguas das etnias predominantes nos municípios, através da apresentação de músicas, receitas, piadas, etc. A participação dos falantes nesses programas de rádio, através de visitas ou ligações, constitui um critério importante, para construir a imagem social da língua. Esse tipo de ação distancia-se, dessa forma, de um problema comum que diz respeito à depreciação da língua minoritária muitas vezes associada ao falar "colono" e "engraçado".

A mídia, no entanto, representa um recurso tecnológico ainda subaproveitado em

ações de promoção e conscientização linguística, seja porque se orienta pelas "leis do mercado", seja porque sua execução exige um aparato específico. Apesar disso, nos 
levantamentos de dados para o , temos observado o impacto social de um programa de rádio na língua local. Os falantes são ouvintes assíduos e regulares. Além disso, a internet, veículo prático e atual de disseminação de informações, é outro meio no qual vídeos e curtametragens em língua minoritária podem ser circulados.

Ainda como incentivo à oralidade, é oportuno ressaltar a relevância de palestras, relatos, apresentações teatrais, enfim, em língua minoritária, em clubes, espaços recreativos, praças públicas e aldeias, destinadas ao público em geral. No caso das línguas que possuem grafia, como as indígenas, é possível desenvolver trabalhos orais e também escritos. Dessa forma, a comunidade pode investir na produção e veiculação de livros infantis ou de memórias, biografias e jornais, escritos na língua minoritária e que apresentem informações, tradições típicas e aspectos da cultura indígena.

De acordo com Appel e Muysken (2005, p. 37), “a prestação de serviços governamentais ou administrativos em línguas minoritárias também pode auxiliar na manutenção linguística" ${ }^{22}$, afinal, dentro de um contexto moderno é comum os indivíduos interagirem com representantes das autoridades locais ou governamentais. Nessa situação, a cooficialização de línguas minoritárias em nível municipal aparece como uma estratégia válida para a manutenção da variedade, afinal são criados novos mecanismos para o uso dessas línguas. Através da cooficialização, criam-se determinadas exigências para implementar a lei, levando a "língua de casa" (de espaços privados) a ocuparem espaços públicos.

Por fim, vale acrescentar que muitas das atividades citadas aqui já são desenvolvidas no Oeste Catarinense, como programas de rádios em línguas minoritárias, oficinas da língua minoritária nas escolas, cooficialização de línguas minoritárias a nível municipal, etc. Surge, assim, a necessidade de valorizar essas ações já existentes através de parcerias com instituições e entidades, entre elas o poder público. Torna-se claro que as ações já praticadas precisam ser mais bem aproveitadas e difundidas.

\section{Estratégias de manutenção das línguas minoritárias na família}

No processo de substituição linguística, cabe lembrar que a maioria dos grupos minoritários não apresentam uma homogeneidade interna clara; pelo contrário, compõem-se de diferentes subgrupos e atitudes frente ao uso da(s) língua(s). O mesmo se aplica, muitas

\footnotetext{
${ }^{12}$ No original: "Governamental or administrative services in the mother tongue can stimulate maintenance". (Tradução livre).
} 
vezes, ao próprio contexto familiar. A família constitui a esfera mais importante para a manutenção das línguas minoritárias.

A importância do uso da língua minoritária como "língua da interação na família" é atestada por uma série de estudos (cf. ROMAINE, 2005). As mudanças sociais, contudo, têm alterado o perfil da família. O tipo de família tradicional não é mais uma obviedade, embora no meio rural, justamente o mais favorável à manutenção linguística. Com a urbanização e as mudanças nas relações de trabalho tem-se tornado cada vez mais comum reduzir-se o contato dos pais com os filhos. Isso redireciona o foco para o conjunto das pessoas de contato dos filhos, que pode incluir, por exemplo, babás que sejam falantes da mesma língua minoritária da família.

No âmbito familiar, é preciso salientar a relevância da estratégia de contação de histórias, ou a leitura à noite, antes de dormir. Como há uma relação afetiva mais forte, pais e avós podem contar às crianças e jovens diferentes histórias, em diferentes momentos, de forma a cultivar práticas sociais que tenham por foco, por exemplo, "causos ao redor do fogão à lenha". A tipologia de temas para estimular esse tipo de histórias vai desde histórias da ocupação da região, de personagens do passado e da formação das cidades e vilas, até causos humorísticos, receitas culinárias, memórias e lembranças individuais e familiares, como aquelas relacionadas ao tempo vivido em outra região, mitos, lendas e fatos reais que os mais antigos conhecem, experiências no trabalho, vivências na escola, festas típicas da família ou da comunidade, práticas religiosas, doenças e tratamentos na medicina popular, tecnologia e perspectivas futuras, além de sobretudo aspectos da própria língua, como por exemplo modos de falar distintos ${ }^{13}$.

Na promoção de uma língua de existência essencialmente oral, cresce o significado de práticas de uso escrito. Projetos de revitalização linguística carecem muitas vezes de materiais que ainda precisam ser escritos. Isso vale, por exemplo, para os livros de receitas culinárias da família que são passados ao longo das gerações, geralmente para as mulheres ou mães, mas que dependendo da estrutura familiar também podem ser passadas para os pais, e os livros de histórias que buscam resgatar as memórias de uma família. Trata-se de produções artesanais, com imagens, fotos e colagens, escritas na língua minoritária mesmo com domínio parcial das regras de escrita.

\footnotetext{
${ }^{13}$ Um recente projeto de pesquisa intitulado "Línguas em contato em Chapecó: etnotextos" (cf. KLEIN e HORST, 20142015) procurou coletar textos orais e escritos como forma de revitalização de culturas que envolvem línguas minoritárias e posterior documentação histórica e social para ser utilizada em manuais escolares.
} 


\section{Considerações finais}

Como se pôde constatar nos históricos das localidades apresentados em sites de prefeituras, o discurso oficial faz referência aos grupos étnicos e, com isso, às culturas e línguas locais, de uma forma bastante depurada que prioriza práticas culturais de valor simbólico para a identidade e historicidade local. A diversidade linguística recua, deste modo, para uma posição secundária, que paulatinamente vai dispensar a língua de seu uso em favor de outros ícones. Com isso, se abre o caminho para a substituição linguística.

Para revitalizar e salvaguardar a língua minoritária, defendeu-se a partir do exposto a necessidade de, acima de tudo, recolocar a língua do grupo nas práticas linguísticas diárias, respeitando sua forma e significado sócio-histórico. Foram analisadas sugestões práticas a partir de experiências prévias, que se dividem em três âmbitos, nos domínios da escola, da vida social da comunidade e da família.

\section{REFERÊNCIAS}

ALTENHOFEN, Cléo Vilson. Os contatos linguísticos e seu papel na arealização do português falado no Sul do Brasil. In: ELIZAINCÍN, Adolfo \& ESPIGA, Jorge (orgs). Español y portugués: fronteiras e contatos. Pelotas: UCPEL, 2008, p. 129-164.

APPEL, René; MUYSKEN, Pieter. Language contact and bilingualism. Amsterdam: Amsterdam Academic Archive, 2005.

BORTOLOTO, Paula Merlo. O talian na fala dos ítalo-brasileiros em chapecó - sc e pato branco - pr: manutenção e substituição dos termos de parentesco. Dissertação de Mestrado PPGEL, UFFS, Chapecó. 2015.

BROCH, Ingrid. Ações de promoção da pluralidade linguística em contextos escolares. Tese (Doutorado) - Curso de Estudos da Linguagem, UFRGS, Porto Alegre, 2014.

CURIOLETTI, Daiane Savoldi. Lusismos no inglês em comunidades bilíngues português / italiano no oeste catarinense: a realização do /r/. Dissertação de Mestrado - PPGEL, UFFS, Chapecó. 2015.

D’ ANGELIS, Wilmar R. Línguas Jê: estudos vários. Londrina: Ed. UEL, 2002.

EBERHARD, David. Em defesa das línguas minoritárias do Brasil. Associação Internacional de Linguística - Sil, Anápolis - Goiás, 2013.

FRIZZO, Celina Eliane. Manutenção, preservação e perda do bilinguismo; português/guarani/kaingang na Reserva Indígena Guarita- RS. Dissertação de Mestrado PPGEL, UFFS, Chapecó (2017).

HAWKINS, Eric. Awareness of language: an introduction. Cambridge: Cambridge University Press, 1984.

HEYE, Jürgen. Sobre o conceito de diglossia. In: GORSKI e COELHO (Orgs). Sociolinguística e ensino. Florianópolis: UFSC, 2006. p. 69-81.

HORST, Cristiane; KRUG, Marcelo J. Identidade e comportamento étnico linguístico em um contexto multilíngue no sul do Brasil: teoria e prática. Nonada, Porto Alegre, n. 24, p. 173$187,2015$. 
KLEIN, Daniele; HORST, Cristiane. A percepção do indivíduo bilíngue hunsriqueanoportuguês sul-riograndense em relação ao seu bilinguismo no oeste de Santa Catarina. In: Web-Revista SOCIODIALETO, v. 6, p. 29-68, 2015.

KRUG, Marcelo Jacó; HORST, Cristiane; WEPIK, Fernanda Fátima. Code-switching na fala de polono-brasileiros de Áurea/RS. In: Revista Domínios de Lingu@gem, v. 10, p. 14041443, 2016.

NASCIMENTO, Glória Cristina Cornélio do. Mestre dos mares: o saber do território, o território do saber na pesca artesanal. In: CANANÉA, F. A. Sentidos de leitura: sociedade e educação. João Pessoa: Imprell, 2013, p. 57-68.

OLIVEIRA, Gilvan Muller. Plurilinguismo no Brasil. Brasília: IPOL, julho de 2008.

PAIM, Elison Antônio. Aspectos da constituição histórica da região Oeste de Santa Catarina. Saeculum: Revista de História, João Pessoa, jan-jun. 2006. p. 121-138.

PREFEITURA MUNICIPAL DE CUNHATAÍ. Disponível em: $<$ http://www.cunhatai.sc.gov.br/cms/pagina/ver/codMapaItem/11203>. Acesso em 15 de set. de 2016.

PREFEITURA MUNICIPAL DE SÃO JOÃO DO OESTE. Disponível em: <http://www.saojoao.sc.gov.br/cms/pagina/ver/codMapaItem/9656>. Acesso em 15 de set. de 2016.

PREFEITURA MUNICIPAL DE VARGEÃO. Disponível em: <http://www.vargeao.sc.gov.br/ cms/pagina/ver/codMapaItem/15422>. Acesso em 15 de set. de 2016.

RADIN, José Carlos. Italianos e Ítalo-Brasileiros na colonização do Oeste Catarinense. 2. Ed. Joaçaba: Edições UNOESC, 2001. 188 p.

ROMAINE, Suzanne. Bilingualism. 2. Ed. Oxford: Basil Blackwell, 1995.

RUSCHEINSKY, Elena Wendling. Uma vez falando em alemão: o uso da variante 'uma vez' em Itapiranga - SC. Dissertação de Mestrado - PPGEL, UFFS, Chapecó. 2014.

SALVARO, Talita Daniel. Cultura, Identidade e Memória no estudo na História Indígena. In: . De geração em geração e o lápis na mão: o processo de revitalização da língua kaingáng na educação escolar indígena/Terra Indígena Xapecó - SC. Florianópolis, 2009. 170 f. Dissertação (Mestrado) - Universidade Federal de Santa Catarina, Centro de Filosofia e Ciências Humanas. Programa de Pós-Graduação em História. 2009.

SCHOLTZ, Adriana de Jesus. Identidade linguística:descendentes de poloneses e ucranianos em contato com o português em Virmond e Candói, no Paraná. Dissertação de Mestrado PPGEL, UFFS, Chapecó. 2014.

SELLA, Aparecida Feola; BUSSE, Sanimar. Uma análise das crenças e atitudes linguísticas dos falantes do oeste do Paraná. In: Revista Signum: Estudos da Linguagem. v. 15, n. 1. 2012.

WEHRMANN, Clarí. A situação do alemão em Tunápolis e em Cunha Porã, Santa Catarina: Dimensão Diarreligiosa. Dissertação de Mestrado - PPGEL, UFFS, Chapecó. 2016.

WEPIK, Fernanda Fátima. Crenças e atitudes linguísticas de polono-brasileiros de Áurea/RS e Nova Erechim/SC: o uso dos termos de parentesco. Dissertação de Mestrado - PPGEL, UFFS, Chapecó. 2017.

WOLSCHICK, Isaura. Aspectos do bilinguismo alemão-português nas comunidades de Mondaí e São João do Oeste - SC. Dissertação de Mestrado - PPGEL, UFFS, Chapecó. 2016. 